\title{
BMJ Open Patterns of high-risk prescribing and other factors in relation to receipt of a home medicines review: a prospective cohort investigation among adults aged 45 years and over in Australia
}

\author{
Wei Du, ${ }^{1}$ Danijela Gnjidic, ${ }^{2,3}$ Sallie-Anne Pearson, ${ }^{4}$ Sarah N Hilmer, ${ }^{5}$ \\ Andrew J McLachlan, ${ }^{2}$ Fiona Blyth, ${ }^{6}$ Rosalie Viney, ${ }^{7}$ Grace Joshy, ${ }^{\odot 1}$ Cathy Day, ${ }^{1}$ \\ Emily Banks ${ }^{1,8}$
}

To cite: Du W, Gnjidic D, Pearson S-A, et al. Patterns of high-risk prescribing and other factors in relation to receipt of a home medicines review: a prospective cohort investigation among adults aged 45 years and over in Australia. BMJ Open 2019;9:e027305. doi:10.1136/ bmjopen-2018-027305

- Prepublication history and additional material for this paper are available online. To view these files, please visit the journal online (http://dx.doi. org/10.1136/bmjopen-2018027305).

Received 16 0ctober 2018 Revised 27 December 2018 Accepted 4 January 2019
Check for updates

\section{(C) Author(s) (or their} employer(s)) 2019. Re-use permitted under CC BY-NC. No commercial re-use. See rights and permissions. Published by BMJ.

For numbered affiliations see end of article.

Correspondence to

DrWei Du; Wei.Du@anu.edu.au

\section{ABSTRACT}

Objectives To quantify the relationship between home medicines review (HMR) receipt in older adults and sociodemographic, medication-related and health factors. Design Prospective cohort analysis.

Settings, participants, measurements Questionnaire data from a population-based cohort study of individuals aged $\geq 45$ years, Sydney, Australia were linked with primary healthcare data, medication and hospitalisation data, to ascertain factors associated with HMR receipt during the period July 2009-June 2014. Medicationrelated factors included exposure to five and more medications (polypharmacy), narrow therapeutic index medicines, potentially inappropriate prescribing defined using Beers Criteria medicines, and anticholinergic and sedative drugs, defined using the Drug Burden Index (DBI). Poisson and Cox regression models were used to evaluate HMR receipt in relation to sociodemographic, behavioural and health characteristics, and time-varying factors including medication use and hospitalisations.

Primary outcome HMR receipt during the 5-year study period.

Results Over 5 years of follow-up, 4.7\% ( $n=6115)$ of 131483 participants received at least one HMR. Five-year HMR receipt was: $1.5 \%$ in people using $<5$ medications at baseline, $6.8 \%$ with $5-9$ medications, $12.7 \%$ with $\geq 10$ medications, $8.8 \%$ using Narrow Therapeutic Index medicines, $6.8 \%$ using Beers Criteria potentially inappropriate medicines and $7.4 \%$ using DBI medicines. Age-sex stratified HRs for HMR receipt were 6.07 ( $95 \% \mathrm{Cl}$ : 5.58 to 6.59 ) and 12.46 (11.42 to 13.59) for concurrent use of 5-9 and $\geq 10$ versus $<5$ medications, respectively. The age-sex adjusted rate ratio for HMR receipt was 2.65 (2.51 to 2.80) with poor versus good self-reported health; this association was attenuated substantially following additional adjustment for polypharmacy.

Conclusions HMR was common in individuals using multiple medications, a formal indication for general practitioner referral and, to a lesser extent, with poorer health and other markers of high-risk prescribing. Despite this, HMR use over a 5-year period was generally below $10 \%$, even in high-risk groups, suggesting

\section{Strengths and limitations of this study}

- This study investigated prospectively the relation of home medicines review (HMR), which is conducted by an accredited pharmacist after referral from a general practitioner with the aim to promote quality use of medicines and reduce adverse medication events, to a range of previously uninvestigated factors using validated measures based on a large sample cohort.

- A series of time-varying analyses when updating medication exposure during the study period provided robust effect estimates of factors widely reported on HMR receipt.

- There is a caveat to the results' interpretation in that influence by unmeasured factors such as precise daily dose and comorbidity burden has not been completely excluded.

substantial potential for improvement in uptake and targeting.

\section{INTRODUCTION}

Adverse medication events are common in older adults and result in considerable morbidity and mortality. ${ }^{1-3}$ The home medicines review (HMR), also referred to as domiciliary medication management review, is an Australian government-funded Medicare Benefits Schedule (MBS) service, subsidised since 2001 with the aim of enhancing appropriate medicine use for community dwelling adults. ${ }^{45}$ This collaborative service involves patients, their general practitioner (GP) and pharmacist, whereby GPs refer their patients to an accredited pharmacist, who then conducts an interview with the patient and generates a written report for the GP, to support discussion of medication 
management plans with patients. ${ }^{5}$ At present, evidence regarding medication review in hospital, primary care and nursing home settings is limited, with some findings suggesting that HMR reviews are associated with reductions in certain adverse events and/or health services use related to medication use. ${ }^{67}$ Current evidence in Australia to support HMR services are based on demonstrated benefits of quality use of medicines ${ }^{8}$ and improved health outcomes. ${ }^{9}$ For example, individuals with heart failure who receive an HMR have a longer time to next hospitalisation for heart failure than those who have not had an HMR. ${ }^{10}$ Furthermore, lower rates of warfarin associated bleeding and occurrence of medication-related adverse events in those receiving versus not receiving an HMR has been reported. ${ }^{11}$

Current recommendations advise that an HMR should be conducted among patients taking five or more medicines (commonly termed polypharmacy), taking medications with a Narrow Therapeutic Index (NTI), attending different doctors, being recently discharged from hospital, having a culturally and linguistically diverse background and/or experiencing physical and cognitive difficulties managing their medication regimens. ${ }^{4} 1213$ Despite the quarterly forecast of 42000 HMR services and an annual reimbursement of $\$ 175$ million by $2020,{ }^{14}$ data on who is receiving the services and whether or not they are being appropriately targeted in the general population are not currently available. In particular, it is unclear whether HMRs are being targeted towards those people with markers of high-risk prescribing, especially among older adults, given the risks of widespread inappropriate medication use. ${ }^{1-3}$

Receiving an HMR appears to vary according to patient characteristics. Older men, and individuals from culturally and linguistically diverse backgrounds are less likely to receive an HMR than individuals without these characteristics. ${ }^{4}$ Previous qualitative studies indicate that GPs' knowledge of HMR processes and time constraints may limit HMR uptake. ${ }^{1516}$ In clients of the Australian Department of Veterans Affairs (DVA), HMR receipt was more common in females, individuals with dementia, heart failure, diabetes, lower socioeconomic status, higher number of medications and higher number of GP visits, and those who have been hospitalised, compared with other members of the population. ${ }^{17}$ However, in spite of studies targeting pharmacists and GPs to improve HMR uptake, ${ }^{18} 19$ it is unclear if recommendations in terms of HMR utilisation are being followed based on person-level data. Therefore, the aim of this study is to investigate factors in relation to HMR receipt in an older Australian cohort, focusing particularly on medication-related factors to inform policies and strategies to improve HMR delivery.

\section{METHODS}

\section{Data sources}

The Sax Institute's 45 and Up Study is a population-based prospective cohort study comprising 267153 participants in New South Wales (NSW). ${ }^{20}$ The 45 and Up Study participants comprising both middle aged and older adults, referred here as older adults, were randomly selected from the Department of Human Services enrolment database and joined the study by completing a postal questionnaire distributed between 2006 and 2009 . Participants provided consent for linkage of questionnaire data to a range of health data collections including the national MBS and Pharmaceutical Benefits Scheme (PBS) records, the NSW admitted patient data collection (APDC) and the NSW Register of Births, Deaths and Marriages (RBDM) records. The NSW Centre for Health Record Linkage provided the linked administrative data with false-positive rate of $<0.5 \%$ and false-negative rate of $<0.1 \% .^{21}$ Details of the study including the questionnaires, sampling frame and linkage methods have been described elsewhere. ${ }^{20-22}$

This study used the 45 and Up Study baseline questionnaire data linked to routinely collected data from a range of other sources, comprising information on sociodemographic characteristics, behavioural factors, self-reported health conditions (questionnaire); dispensing records of subsidised prescription medications (PBS), receipt of HMR (MBS), hospitalisations (APDC) and deaths (RBDM). In recognition of changing practice over time after the landmark HMR review in $2008,{ }^{4}$ we set the 5 -year period of observation for HMR receipt from 1 July 2009 to 30 June 2014 to ensure that cohort members were followed over the same calendar period. We also defined an additional 'baseline' exposure period, covering the 3 months immediately prior to the 5 year observation period (ie, the 3 months prior to 1 July 2009).

\section{Study population}

PBS data provide complete medication dispensing records on those who hold healthcare concession cards. ${ }^{23}$ PBS data on other population members, termed 'general beneficiaries' prior to April 2012 do not provide complete dispensing records as they only comprise dispensing records for medicines priced higher than the patient co-payment. Hence, we restricted the analysis to healthcare concession card holders based on PBS records to get a complete medication dispensing records. Among 155348 concessional beneficiaries recorded in the PBS data at any time during the study period, we excluded participants whose initial PBS-derived social security beneficiary status was non-concessional $(n=20077)$. We excluded another 16 participants as their PBS medication records were unclassifiable over the study period. Because HMR is only applicable to community-dwelling individuals, we further excluded those who self-reported as living in residential aged care facilities in the 45 and Up Study questionnaire $(\mathrm{n}=1106)$. Participants who held DVA healthcare cards were also excluded $(n=2658)$, as PBS did not capture their subsidised prescription medication records. After exclusion of eight participants without any MBS records, the final study population comprised 131483 concession card holders (figure 1). 


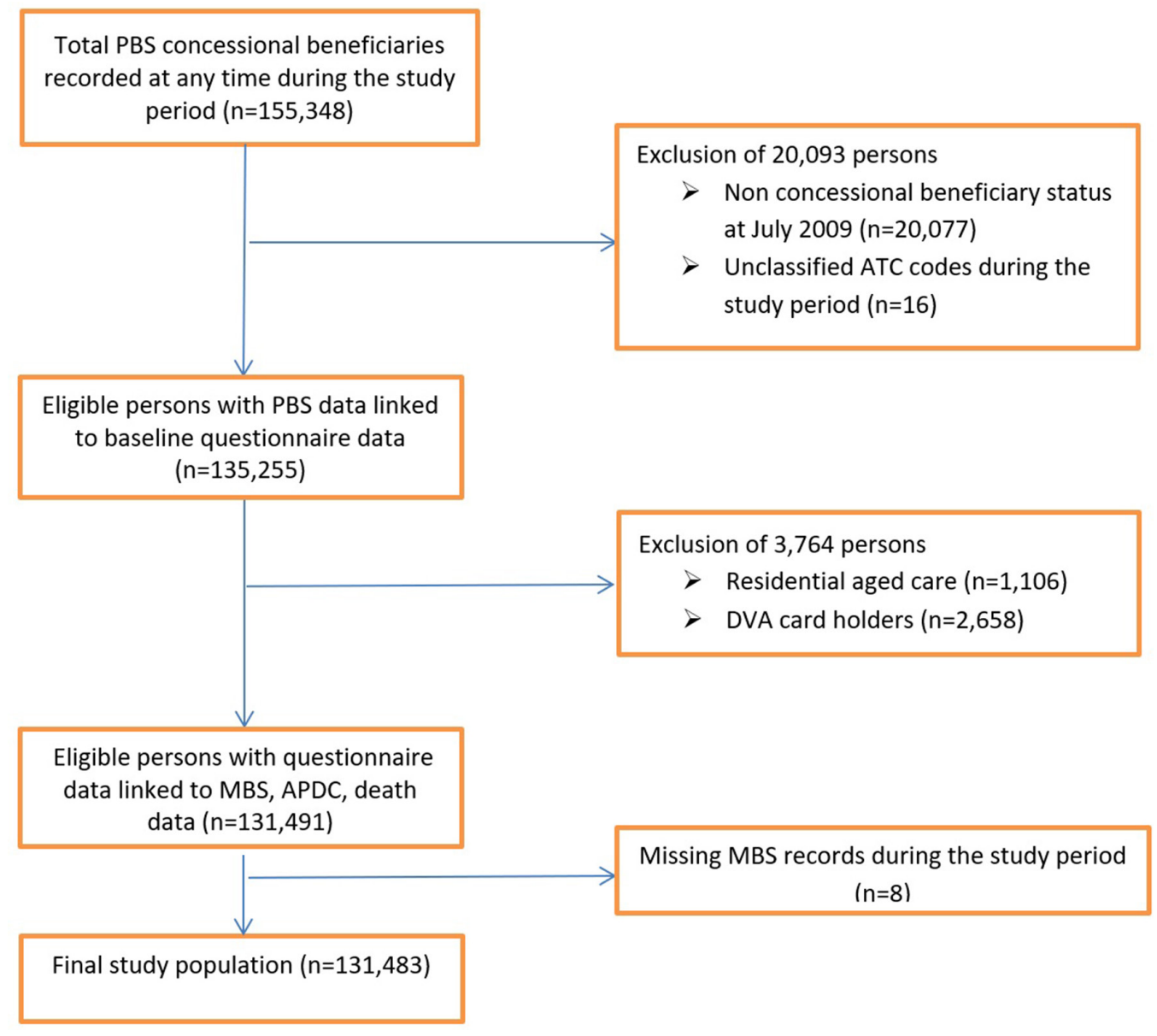

Figure 1 Study participants inclusion and exclusion. APDC, admitted patient data collection; ATC, Anatomic Therapeutic Chemical; DVA, Department of Veterans' Affairs; MBS, Medicare Benefits Schedule; PBS, Pharmaceutical Benefits Scheme.

We used the linked MBS records to determine the first occurrence of HMR during the 5-year period (item number: 900) ${ }^{12}$ which was set as yes or no. The MBS records available for these analyses included the date the HMR was conducted (the HMR service date); no data on the date that the patient was referred by their GP for the HMR were available. There may be up to 90 days from the date of referral to the date that the HMR is conducted by the pharmacist. ${ }^{13}$ Although medication use and other factors at the time of referral would most accurately reflect those on which the GP made the decision that an HMR was necessary, the exact date of HMR referral date was not available; hence, we used the HMR service date as the best available measure for analyses relating to time of HMR occurrence. However, this approach could allow a minor degree of reverse causality/measurement error to contribute to the results, for example, medication exposure could possibly be influenced by the GP consultation when the referral for the HMR was made or use of medications could change for some other reason during the period between referral and HMR occurrence. Therefore, we conducted a sensitivity analysis backdating the HMR occurrence by 90 days prior to the HMR service date, assuming that the real date when necessity of HMR was recommended is likely to fall within this 3-month period. ${ }^{13}$ We censored data if participants died, had markers of a residential aged care admission ${ }^{12}$ or their PBS beneficiary status became non-concessional, during the study period.

We used the Andersen-Newman model to classify self-reported characteristics potentially influencing receipt of HMR into three broad groups. ${ }^{24}$ Predisposing factors included age group in years (ie, 45-49, 50-54, $55-59,60-64,65-69,70-74,75-79,80-84,85$ years and over); sex, as male or female; Language Other Than English (LOTE) spoken at home, as yes or no; marital status, as married/de facto or single; educational attainment, as no school certificate, school certificate, trade or diploma, or degree or higher; smoking, as current, past or never; alcohol consumption, as 0 drinks, 1-14 drinks or $\geq 15$ drinks per week; and body mass index (BMI) $\left(\mathrm{kg} / \mathrm{m}^{2}\right)$, as underweight $(15$ to $<18.5)$, normal weight (18.5 to $<25)$, overweight $(25$ to $<30)$ or obese $(\geq 30)$. Enabling factors included remoteness of residence using the postcode-based Accessibility Remoteness Index for Australia (ARIA+) scores ${ }^{25}$ as metropolitan, regional or remote areas; annual household income, as $<\$$ A20 000, $\$ A 20000-\$ A 69000$ or $\geq \$ A 70000$; private health insurance, as yes or no; and paid work status as yes or no. Health-need factors included functional limitation using the 
Table 1 Study population characteristics at July 2009

Proportion (\%) and number of medications in 3 months prior to July 2009†

\begin{tabular}{|c|c|c|c|}
\hline \multirow{2}{*}{ Characteristics* } & \\
\hline & $0-4$ & $5-9$ & $\geq 10$ \\
\hline Total & 53.6 (70 537) & 34.4 (45 283) & $11.9(15663)$ \\
\hline \multicolumn{4}{|l|}{ Age group (years) } \\
\hline $45-49$ & $75.9(4127)$ & $18.5(1006)$ & $5.5(301)$ \\
\hline $50-54$ & $70.4(5135)$ & $22.7(1654)$ & $7.0(510)$ \\
\hline $55-59$ & $67.0(8015)$ & $24.9(2976)$ & $8.1(970)$ \\
\hline $60-64$ & $65.2(14855)$ & $26.9(6129)$ & $7.9(1790)$ \\
\hline $65-69$ & $57.4(16$ 132) & 33.5 (9395) & $9.1(2555)$ \\
\hline $70-74$ & 47.7 (10 244) & $39.3(8447)$ & $13.0(2787)$ \\
\hline $75-79$ & $38.4(5883)$ & $43.8(6709)$ & $17.7(2715)$ \\
\hline $80-84$ & $33.0(4667)$ & $46.8(6612)$ & $20.2(2856)$ \\
\hline$\geq 85$ & 29.5 (1479) & $47.0(2355)$ & 23.5 (1179) \\
\hline \multicolumn{4}{|l|}{ Sex } \\
\hline Male & 54.4 (32 274) & $34.4(20410)$ & $11.3(6683)$ \\
\hline Female & 53.1 (38 263) & 34.5 (24 873) & $12.5(8980)$ \\
\hline \multicolumn{4}{|l|}{$\begin{array}{l}\text { Language Other Than } \\
\text { English }\end{array}$} \\
\hline No & 53.9 (63 799) & 34.5 (40 815) & $11.7(13853)$ \\
\hline Yes & $51.8(6738)$ & $34.3(4468)$ & $13.9(1810)$ \\
\hline \multicolumn{4}{|l|}{ Marital status } \\
\hline Partnered & $55.9(50794)$ & 33.4 (30 320) & $10.7(9734)$ \\
\hline Single & 48.5 (19 318) & $36.9(14676)$ & $14.6(5811)$ \\
\hline \multicolumn{4}{|l|}{ Education } \\
\hline No school certificate & 43.2 (9898) & 39.9 (9162) & $16.9(3874)$ \\
\hline School certificate & 52.7 (25 286) & 35.4 (16 982) & $11.8(5680)$ \\
\hline Trade or diploma & $56.9(23099)$ & 32.7 (13 278) & $10.4(4208)$ \\
\hline Degree or higher & $64.2(10929)$ & $27.7(4709)$ & $8.1(1386)$ \\
\hline \multicolumn{4}{|l|}{ Residence } \\
\hline Metro & 50.5 (27 255) & 35.9 (19 370) & $13.6(7331)$ \\
\hline Regional & 55.9 (41 872) & 33.4 (25 022) & $10.7(8001)$ \\
\hline Remote & $53.2(1371)$ & $34.2(882)$ & $12.6(325)$ \\
\hline
\end{tabular}

Annual household

income $(\$ A)$

\begin{tabular}{|lllc}
\hline$<20000$ & $45.3(20362)$ & $39.2(17606)$ & $15.4(6937)$ \\
\hline $20000-69999$ & $61.1(29365)$ & $30.7(14743)$ & $8.2(3944)$ \\
\hline 70000 & $79.2(4311)$ & $17.1(931)$ & $3.7(203)$ \\
\hline Private insurance & & & \\
\hline No & $50.7(32144)$ & $35.9(22778)$ & $13.5(8535)$ \\
\hline Yes & $56.4(38390)$ & $33.1(22502)$ & $10.5(7126)$ \\
\hline Paid work & & & \\
\hline No & $47.4(48135)$ & $38.5(39070)$ & $14.2(14389)$ \\
\hline Yes & $75.0(22402)$ & $20.8(6213)$ & $4.3(1274)$ \\
\hline Smoking & & & \\
\hline Never & $55.9(40271)$ & $33.5(24156)$ & $10.5(7585)$ \\
\hline Past & $49.4(24302)$ & $36.5(17988)$ & $14.1(6925)$ \\
\hline Current & $58.7(5742)$ & $30.3(2962)$ & $11.0(1074)$ \\
\hline Alcohol drinks (per week) & & & \\
\hline 0 & $48.3(24636)$ & $36.7(18719)$ & $15.0(7639)$ \\
\hline $1-14$ & $57.6(34$ 838) & $32.7(19749)$ & $9.7(5844)$ \\
\hline$\geq 15$ & $58.1(9412)$ & $32.7(5298)$ & $9.2(1486)$ \\
\hline
\end{tabular}

Continued
Table 1 Continued

Proportion (\%) and number of medications in 3 months prior to July 2009†

$\begin{array}{llll}\text { Characteristics }^{*} & 0-4 & 5-9 & \geq 10\end{array}$

BMI $\left(\mathrm{kg} / \mathrm{m}^{2}\right)$

$\begin{array}{llll}\text { Normal } & 61.4(26158) & 29.9(12751) & 8.7(3728) \\ \text { Underweight } & 57.3(1014) & 31.1(551) & 11.6(205) \\ \text { Overweight } & 54.5(25852) & 34.8(16526) & 10.7(5082) \\ \text { Obese } & 42.5(11993) & 39.8(11223) & 17.7(4994)\end{array}$

Physical functioning impairment

$\begin{array}{lllr}\text { No } & 78.3(18551) & 19.2(4541) & 2.6(608) \\ \text { Minor } & 68.1(20049) & 27.7(8152) & 4.2(1225) \\ \text { Moderate } & 47.9(16063) & 41.0(13774) & 11.1(3721) \\ \text { Severe } & 25.8(5748) & 44.4(9883) & 29.8(6633)\end{array}$

Psychological distress

\begin{tabular}{|c|c|c|c|}
\hline Low & 59.7 (49 727) & 32.0 (26 648) & 8.4 (6968) \\
\hline Moderate & $48.4(8087)$ & 35.9 (5999) & 15.7 (2629) \\
\hline High & $42.4(4158)$ & 36.7 (3602) & $20.9(2045)$ \\
\hline \multicolumn{4}{|c|}{ Hearing impairment } \\
\hline No & $57.1(38$ 920) & $32.6(22$ 236) & $10.3(7039)$ \\
\hline Yes & $50.1(29461)$ & $36.4(21372)$ & $13.5(7936)$ \\
\hline \multicolumn{4}{|c|}{ Memory impairment } \\
\hline No & $56.6(55783)$ & $32.9(32431)$ & $10.5(10311)$ \\
\hline Yes & 44.4 (12 318) & $39.3(10891)$ & $16.3(4528)$ \\
\hline \multicolumn{4}{|c|}{ Vision impairment } \\
\hline No & 56.7 (57 265) & $33.2(33551)$ & $10.1(10$ 164) \\
\hline Yes & $42.6(10618)$ & 38.7 (9645) & $18.6(4640)$ \\
\hline \multicolumn{4}{|c|}{ Self-reported cancers } \\
\hline No & $55.4(58706)$ & $33.5(35460)$ & $11.2(11819)$ \\
\hline Yes & $46.4(11831)$ & 38.5 (9823) & $15.1(3844)$ \\
\hline
\end{tabular}

Self-reported circulatory diseases

\begin{tabular}{|lllr}
\hline No & $60.1(63722)$ & $31.2(33045)$ & $8.7(9242)$ \\
\hline Yes & $26.8(6815)$ & $48.0(12238)$ & $25.2(6421)$ \\
\hline Self-reported diabetes & & & \\
\hline No & $58.1(67131)$ & $32.5(37495)$ & $9.4(10866)$ \\
Yes & $21.3(3406)$ & $48.7(7788)$ & $30.0(4797)$ \\
\hline Self-reported poor health & & & \\
No & $60.6(61630)$ & $32.0(32552)$ & $7.4(7557)$ \\
\hline Yes & $26.7(6399)$ & $43.7(10494)$ & $29.6(7104)$
\end{tabular}

Beers Criteria list medicines $\dagger$

$\begin{array}{lccc}\text { No } & 77.5(50898) & 20.3(13347) & 2.2(1464) \\ \text { Yes } & 29.9(19639) & 48.6(31936) & 21.6(14199)\end{array}$

NTI medicinesł‡

$\begin{array}{lllr}\text { No } & 60.4(66087) & 31.7(34713) & 7.9(8595) \\ \text { Yes } & 20.2(4450) & 47.8(10570) & 32.0(7068)\end{array}$

Drug Burden Index medicines $\uparrow$

$\begin{array}{lccc}\text { No } & 70.3(57804) & 25.9(21257) & 3.8(3119) \\ \text { Yes } & 25.8(12733) & 48.7(24026) & 25.4(12544)\end{array}$

Number of different doctors $†$

\begin{tabular}{lccc}
$\leq 2$ & $74.9(40580)$ & $22.3(12061)$ & $2.9(1558)$ \\
3 or 4 & $50.8(18328)$ & $39.7(14313)$ & $9.5(3419)$ \\
$\geq 5$ & $28.2(11629)$ & $45.9(18909)$ & $25.9(10686)$ \\
\hline
\end{tabular}

Continued 


\begin{tabular}{llll}
\hline Table 1 Continued \\
\hline \multicolumn{4}{c}{$\begin{array}{l}\text { Proportion (\%) and number of medications in } \\
\text { 3 months prior to July 2009† }\end{array}$} \\
\cline { 2 - 4 } Characteristics* & $\mathbf{0 - 4}$ & $\mathbf{5 - 9}$ & $\geq \mathbf{1 0}$ \\
\hline Hospitalisation† & & & \\
No & $54.1(70343)$ & $34.4(44769)$ & $11.5(15026)$ \\
Yes & $14.4(194)$ & $38.2(514)$ & $47.4(637)$ \\
HMR (12 months prior) & & & \\
No & $54.1(70409)$ & $34.3(44637)$ & $11.5(15022)$ \\
Yes & $9.0(128)$ & $45.7(646)$ & $45.3(641)$ \\
\hline
\end{tabular}

${ }^{*}$ Missing categories were not presented.

†Data were presented as proportions (and numbers). We used the linked PBS data (April-June 2009), MBS data (April-June 2009) and APDC data (April-June 2009) to identify recent medication use, number of different doctors visited and recent hospitalisation during the 3 months prior to 1 July 2009 , respectively.

$\ddagger$ NTI drugs include digoxin, amiodarone, lignocaine, quinidine, flecainide, mexilitine, salicylate, perhexiline, theophylline, phenytoin, carbamazepine, sodium valproate, phenobarbitone, gentamicin, amikacin, vancomycin, lithium, warfarin, methotrexate, insulin, ciclosporin, levothyroxine, tacrolimus, bupropion, primidone, etravirine, enoxaparin, rivaroxaban, dabigatran, apixaban, cyclosproine, sirolimus, edoxaban, tobramycin and netilmicin. APDC, admitted patient data collection; BMI, body mass index; HMR, home medicines review; MBS, Medicare Benefits Schedule; NTI, Narrow Therapeutic Index; PBS, Pharmaceutical Benefits Scheme.

Medical Outcomes Study Physical Functioning scores, ${ }^{26}$ as no (100), minor (90-99), moderate (60-89) or severe (0-59); psychological distress using the Kessler Psychological Distress Scale (K10) scores, ${ }^{27}$ as low (10-15), moderate (16-21) or high (22-50); hearing impairment, as yes (self-rated fair, poor hearing) or no (excellent, very good, good); vision impairment as yes (self-rated fair, poor vision) or no (excellent, very good, good); memory impairment, as yes (self-rated fair, poor memory) or no (excellent, very good, good); self-reported cancers, as yes or no; self-reported circulatory disease, as yes or no; self-reported diabetes, as yes or no; self-reported poor health, as yes (self-rated fair, poor health) or no (excellent, very good, good). There were no missing data in age, sex or variables sourced from linked data. The proportion of missing data in other variables were: marital status $(0.6 \%)$, education (2.3\%), smoking (0.4\%), alcohol (2.9\%), BMI $(8.7 \%)$, residence $(0.0 \%)$, income $(25.2 \%)$, insurance $(0.0 \%)$, physical functioning impairment $(17.1 \%)$, psychological distress (16.4\%), self-rated health $(4.4 \%)$, hearing impairment (3.4\%), memory impairment $(4.0 \%)$ and vision impairment (4.3\%). A separate category was included for missing values in regression models.

We used the linked PBS medication dispensing records to identify distinct medications based on the Anatomic Therapeutic Chemical classification codes. ${ }^{28}$ We estimated monthly exposure to medicines by assuming date of dispensing plus 90 days as the duration of exposure for each medicine. ${ }^{29}{ }^{30}$ Specifically, if the period of exposure to a drug occurred in any month during the study period, the exposure of that drug was determined as yes. In this study, four markers of high-risk prescribing were considered including exposure to five and more medications (polypharmacy), NTI medicines, potentially inappropriate prescribing defined using Beers Criteria medicines, and anticholinergic and sedative drugs, defined using the Drug Burden Index (DBI) ${ }^{22}$ DBI and Beers drugs were developed for and have been studied in population groups aged 65 years and over. This age cut-off is unlikely to be absolute and DBI and Beers drugs may have clinical implications in vulnerable but younger population groups, such as people living with mental health conditions or cognitive impairment. To explore relations in younger groups, the current setting also included individuals aged 45-64 years, although the majority are over this age range. Given this, caution is necessary in the interpretation and generalisation of the DBI and Beers drugs for people in younger age groups.

We considered cohort baseline medicine exposure (exposure in the 3 months prior to 1 July 2009) to number of medications, categorised as using $\leq 4$ drugs in every month, 5-9 drugs in any of the 3 months or $\geq 10$ drugs or hyperpolypharmacy in any of the 3 months ${ }^{31}$; and any use of the drugs with a high risk or $\mathrm{NTI}^{32}{ }^{33}$ which were categorised as yes or no. Other than these medication-related indications for HMR, we also considered medicine exposures that were potentially inappropriate in older adults, including any use of the medicines on the 2015 Beers criteria list of drugs independent of diseases ${ }^{34}$ and exposure to medicines with clinically significant anticholinergic and/or sedative effects based on the pharmacological risk assessment tool, DBI. ${ }^{35}$ Because PBS data do not provide actual daily dose information, ${ }^{36}$ exposure to DBI drugs was categorised as yes vs no, rather than imputing the daily dose actually taken by an individual participant.

This study used the linked hospitalisation data to identify recent hospitalisation during the 3 months prior to 1 July 2009 (categorised as yes or no), and the MBS data to identify recipients of an HMR (categorised as yes or no during the previous immediate year) and number of different doctors visited during the 3 months prior to 1 July 2009 as the baseline exposures. Because most study participants received different dispensed medicines at different time points during the study period, it is possible that more recent exposure may particularly impact on HMR receipt. We defined exposure to number of medications, medicines with NTI, medicines on the Beers Criteria and medicines included in the DBI as timevarying factors based on whether or not participants were exposed to relevant medication-related factors during any of the 20 quarterly observational windows during the 5 -year study period. We also considered quarterly exposure to hospitalised care based on hospitalisation records and number of different doctors based on MBS records, and therefore allowed participants to change relevant exposure status during the study period.

\section{Statistical analysis}

We calculated the frequencies and proportions of participants exposed to <5, 5-9 and 10 or more medications at baseline according to cohort characteristics. We also 
calculated the proportion of individuals having an HMR during the study period, and crude incidence rates as the number of people receiving at least one HMR per 1000 person-years. We used Poisson regression models with robust error variance to estimate the rate ratios (RR) and 95\% CIs for HMR receipt in relation to individual factors, first adjusted for age and sex only, then further adjusted for the number of medications (ie, $0-4,5-9, \geq 10$ ). We used Cox regression models with robust variance estimate to evaluate the HR for receiving an HMR as an approximation to RR and $95 \% \mathrm{CI}$ for time-varying medication and hospital care exposures, stratified by age and sex. We set $p$ values $<0.05$ as statistically significant. We carried out all analyses using SAS V.9.4.

\section{Sensitivity analysis}

We modelled the HMR receipt using backdated HMR occurrence (ie, HMR date of service minus 90 days) as the outcome variable to mimic the likely exposure scenario when requesting HMR, using binary categorisation for polypharmacy (ie, $\geq 5$ medicines or fewer than 5 ). We compared the distribution of medication use between 3 months before and after 1 July 2009, allowing for potential stockpiling when approaching end of financial year. The majority of participants included in these analyses completed their questionnaires in 2008, meaning that the 'baseline' period over which the medication data were ascertained ( 3 months prior to 1 July 2009) was relatively close in time to the questionnaire-based reporting of their other characteristics. However, to test the possible impact of questionnaire data being further distant from the 'baseline' medication exposure ascertainment we conducted sensitivity analyses excluding participants recruited before 2008. We also examined the effects on the main estimates of excluding participants with historical HMR receipt during July 2006-June 2009, and excluding participants aged $<65$ years at the baseline because Beers criteria and DBI measures were developed for older olds, respectively.

\section{Community and participant involvement}

Participants in the 45 and Up Study receive an annual newsletter informing them of the study progress and projects under way using the study data. The study website is also kept up to date regarding research under way and events. There is no individual feedback to study participants regarding findings or results specific to that individual.

\section{RESULTS}

A total of 131483 participants who were concession card holders were eligible for this study (figure 1). The median age was 68.1 (IQR 13.4) years and less than half $(45.2 \%$, $\mathrm{n}=59367$ ) were men. Figure 2 presents the distribution of monthly numbers of medications at baseline (ie, averaged over the 3 months immediately prior to July 2009) in the cohort. Overall, 53.6\% $(\mathrm{n}=70537)$ of the cohort

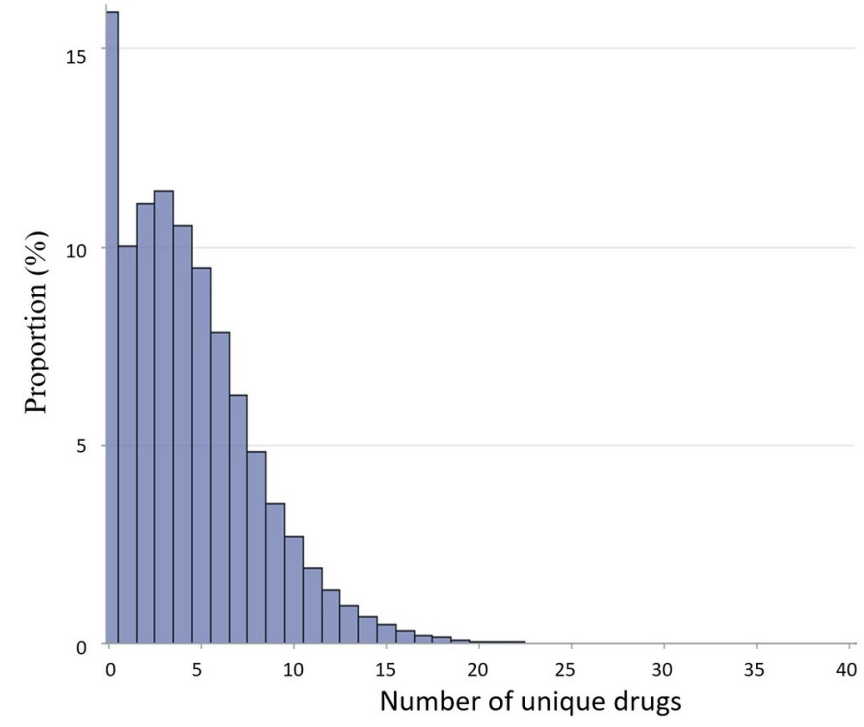

Figure 2 Monthly numbers of unique drugs averaged over a 3-month period immediately prior to July 2009.

used fewer than five medications, $34.4 \%(\mathrm{n}=45283)$ used 5-9 medications and $11.9 \%(\mathrm{n}=15663)$ used 10 or more drugs (termed 'hyperpolypharmacy') (table 1). At baseline $17 \%$ study participants were using NTI medications, and $37 \%$ and $50 \%$ using medications contributing to DBI and Beers criteria, respectively. The distribution of health factors varied among participants using different numbers of medications, with participants experiencing greater morbidity concomitantly using more medicines (table 1).

\section{Population characteristics}

During the study period from July 2009 to June 2014, $4.7 \% \quad(\mathrm{n}=6115)$ of the study cohort received at least one HMR. The proportions receiving at least one HMR during follow-up were $1.5 \%$ (1065/70 537) of those using fewer than five medications monthly at baseline, $6.8 \%$ (3068/45 283) using 5-9 medications, $12.7 \%$ (1982/15 663) using 10 or more medications, $8.8 \%(1941 / 22088)$ of those exposed to medicines with NTI, $6.8 \%(4461 / 65774)$ to potentially inappropriate medications defined using the Beers Criteria and 7.4\% (3648/49 303) of those exposed to medicines included in the DBI pharmacological tool.

The HMR incidence rate increased with age (table 2). After adjustment for age and sex, HMR receipt was strongly associated with taking 5-9 medications, a formal indication for referral (adjusted RR: 4.94; 95\% CI: 4.60 to 5.30 ) and 10 or more medications (adjusted RR: 10.71; 95\% CI: 9.91 to 11.57$)$ compared with $<5$ medications (table 2). Increased HMR receipt was also observed in older people, smokers, those who were single, obese, without private insurance, not in paid work, residing remotely, having morbidity such as diabetes and broader health issues such as impaired physical functioning, compared with other study participants. HMR receipt did not vary significantly between males and females, 
Table 2 Prospective relationship of HMR to factors of interest

\begin{tabular}{|c|c|c|c|c|}
\hline \multirow[b]{2}{*}{ Cohort characteristics } & \multicolumn{2}{|c|}{ Receiving at least one HMR } & \multicolumn{2}{|l|}{ Rate ratios $(95 \% \mathrm{Cl})$} \\
\hline & $\begin{array}{l}\text { Proportion (\%) (n/ } \\
\text { persons) }\end{array}$ & $\begin{array}{l}\text { Crude rate (per 1000) (n/ } \\
\text { person-years*) }\end{array}$ & $\begin{array}{l}\text { Adjusted for age and sex, } \\
\text { where appropriate }\end{array}$ & $\begin{array}{l}\text { Adjusted for age, sex and } \\
\text { number of medication }\end{array}$ \\
\hline \multicolumn{5}{|l|}{ Age group (years) } \\
\hline $45-49$ & $2.2(121 / 5434)$ & $5.2(121 / 23396)$ & 1.00 & 1.00 \\
\hline $50-54$ & $3.2(232 / 7299)$ & $7.2(232 / 32$ 079) & 1.40 (1.12 to 1.74$)$ & 1.23 (0.99 to 1.53$)$ \\
\hline $55-59$ & $3.8(456 / 11961)$ & $8.4(456 / 54251)$ & 1.63 (1.33 to 1.99$)$ & 1.34 (1.10 to 1.63$)$ \\
\hline $65-69$ & $5.3(1500 / 28$ 082) & $11.7(1500 / 128440)$ & 2.27 (1.89 to 2.73 ) & 1.61 (1.34 to 1.93$)$ \\
\hline $70-74$ & $4.9(1042 / 21478)$ & $13.8(1042 / 75532)$ & 2.69 (2.23 to 3.24$)$ & 1.62 (1.34 to 1.96$)$ \\
\hline $75-79$ & $5.2(801 / 15307)$ & $18.5(801 / 43221)$ & 3.61 (2.98 to 4.37$)$ & 1.84 (1.52 to 2.23$)$ \\
\hline $80-84$ & $5.3(753 / 14$ 135) & $20.7(753 / 36461)$ & 4.02 (3.32 to 4.87$)$ & 1.92 (1.59 to 2.33$)$ \\
\hline Female & $4.7(3358 / 72116)$ & $11.8(3358 / 285277)$ & 1.04 (0.99 to 1.09$)$ & 0.95 (0.90 to 1.00$)$ \\
\hline \multicolumn{5}{|l|}{ LOTE } \\
\hline No & $4.6(5462 / 118467)$ & $11.9(5462 / 458594)$ & 1.00 & 1.00 \\
\hline Yes & $5.0(653 / 13$ 016) & $12.8(653 / 51$ 189) & 1.08 (0.99 to 1.17$)$ & 1.00 (0.92 to 1.08$)$ \\
\hline \multicolumn{5}{|l|}{ Marital status } \\
\hline Partnered & $4.5(4069 / 90$ 848) & $11.3(4069 / 359$ 762) & 1.00 & 1.00 \\
\hline Single & $5.0(1986 / 39805)$ & $13.5(1986 / 146$ 910) & 1.15 (1.09 to 1.22$)$ & 1.06 (1.00 to 1.12$)$ \\
\hline \multicolumn{5}{|l|}{ Education } \\
\hline No school certificate & $6.5(1498 / 22$ 934) & $17.5(1498 / 85812)$ & 1.00 & 1.00 \\
\hline Remote & $5.9(153 / 2578)$ & $15.4(153 / 9917)$ & 1.51 (1.28 to 1.78$)$ & 1.43 (1.22 to 1.69$)$ \\
\hline \multicolumn{5}{|l|}{ Income (\$) } \\
\hline$<20000$ & $5.8(2590 / 44905)$ & $15.4(2590 / 168$ 773) & 1.00 & 1.00 \\
\hline 20000-69999 & 3.5 (1672/48 052) & $8.6(1672 / 194231)$ & 0.59 (0.56 to 0.63$)$ & 0.75 (0.71 to 0.80$)$ \\
\hline$\geq 70000$ & $1.5(79 / 5445)$ & $3.4(79 / 23027)$ & 0.26 (0.21 to 0.33$)$ & 0.45 (0.36 to 0.56$)$ \\
\hline \multicolumn{5}{|l|}{ Private insurance } \\
\hline No & $5.5(3519 / 63457)$ & $14.4(3519 / 245$ 192) & 1.00 & 1.00 \\
\hline Yes & $3.8(2594 / 68$ 018) & $9.8(2594 / 264563)$ & 0.64 (0.61 to 0.68$)$ & 0.74 (0.71 to 0.78$)$ \\
\hline \multicolumn{5}{|l|}{ Paid work } \\
\hline No & $5.4(5447 / 101594)$ & $14.3(5447 / 380392)$ & 1.00 & 1.00 \\
\hline Yes & $2.2(668 / 29889)$ & $5.2(668 / 129390)$ & 0.44 (0.40 to 0.48$)$ & 0.65 (0.59 to 0.70$)$ \\
\hline \multicolumn{5}{|l|}{ Smoking } \\
\hline Never & $4.2(3001 / 72$ 012) & $10.8(3001 / 278$ 403) & 1.00 & 1.00 \\
\hline Past & $5.2(2565 / 49215)$ & $13.6(2565 / 188$ 718) & 1.31 (1.24 to 1.39$)$ & 1.11 (1.05 to 1.17$)$ \\
\hline Current & $5.4(525 / 9778)$ & $12.9(525 / 40$ 836) & 1.62 (1.47 to 1.78$)$ & 1.37 (1.24 to 1.50$)$ \\
\hline \multicolumn{5}{|l|}{ Alcohol drinks (per week) } \\
\hline 0 & $5.5(2791 / 50$ 994) & $14.4(2791 / 194$ 393) & 1.00 & 1.00 \\
\hline $1-14$ & $4.0(2438 / 60431)$ & $10.3(2438 / 236441)$ & 0.71 (0.67 to 0.75$)$ & 0.84 (0.80 to 0.89$)$ \\
\hline
\end{tabular}

Continued 
Table 2 Continued

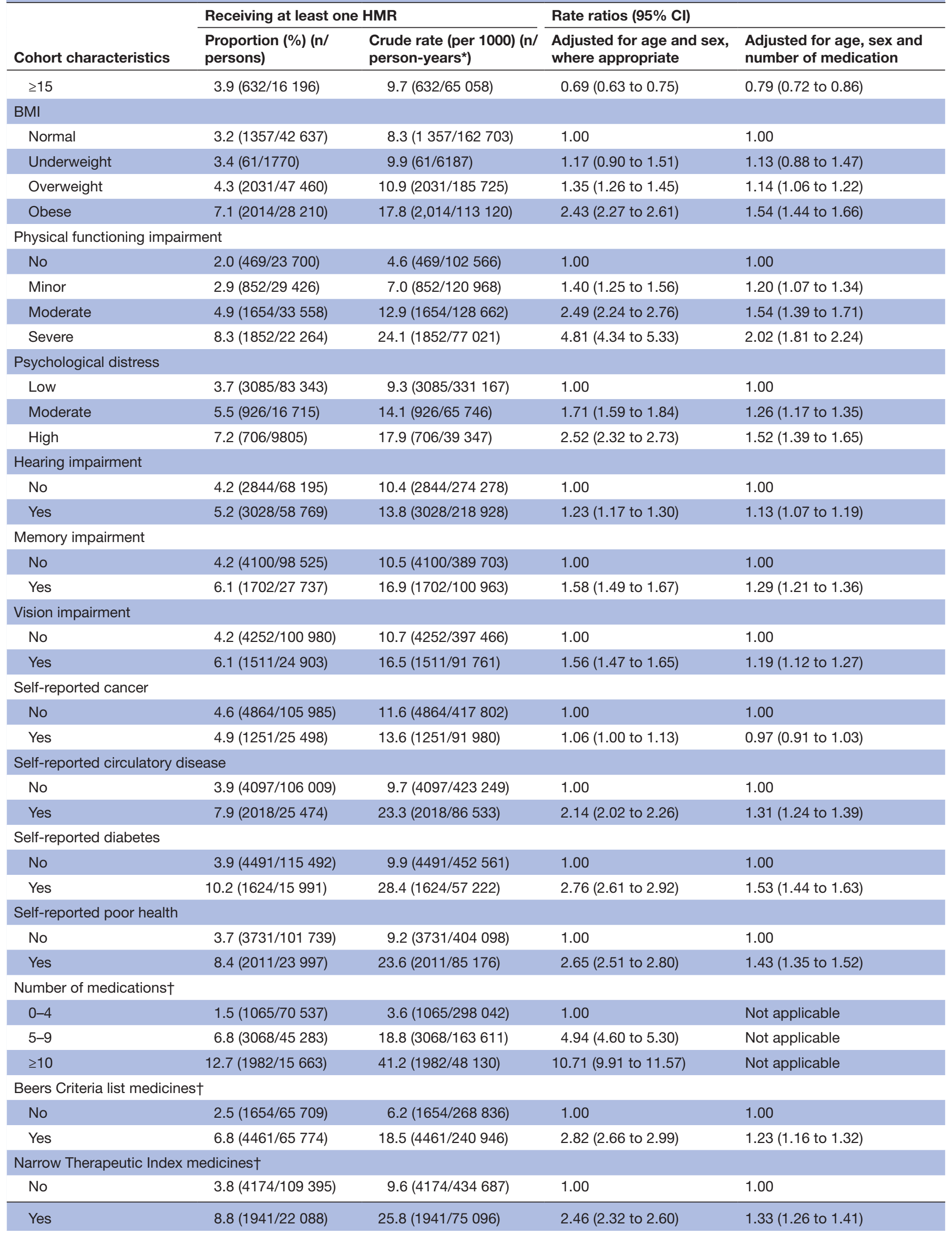


Table 2 Continued

\begin{tabular}{|c|c|c|c|c|}
\hline \multirow[b]{2}{*}{ Cohort characteristics } & \multicolumn{2}{|c|}{ Receiving at least one HMR } & \multicolumn{2}{|l|}{ Rate ratios $(95 \% \mathrm{Cl})$} \\
\hline & $\begin{array}{l}\text { Proportion (\%) (n/ } \\
\text { persons) }\end{array}$ & $\begin{array}{l}\text { Crude rate (per 1000) (n/ } \\
\text { person-years*) }\end{array}$ & $\begin{array}{l}\text { Adjusted for age and sex, } \\
\text { where appropriate }\end{array}$ & $\begin{array}{l}\text { Adjusted for age, sex and } \\
\text { number of medication }\end{array}$ \\
\hline \multicolumn{5}{|c|}{ Drug Burden Index medicines† } \\
\hline No & $3.0(2467 / 82$ 180) & $7.4(2467 / 332$ 105) & 1.00 & 1.00 \\
\hline Yes & $7.4(3648 / 49303)$ & $20.5(3648 / 177677)$ & 2.69 (2.55 to 2.83$)$ & 1.27 (1.20 to 1.35$)$ \\
\hline \multicolumn{5}{|c|}{ Number of different doctors $†$} \\
\hline 3 or 4 & $4.8(1740 / 36060)$ & $12.6(1740 / 138610)$ & 2.08 (1.94 to 2.24$)$ & 1.41 (1.30 to 1.51$)$ \\
\hline$\geq 5$ & $7.5(3090 / 41224)$ & $21.5(3090 / 143476)$ & 3.44 (3.21 to 3.67$)$ & 1.60 (1.49 to 1.72$)$ \\
\hline \multicolumn{5}{|l|}{ Hospitalisation $\dagger$} \\
\hline No & $4.6(6013 / 130138)$ & $11.9(6013 / 506$ 066) & 1.00 & 1.00 \\
\hline Yes & $38.3(542 / 1415)$ & $176.1(542 / 3078)$ & $13.56(12.36$ to 14.86$)$ & 7.23 (6.57 to 7.96$)$ \\
\hline
\end{tabular}

*Total person-years were rounded to the nearest integer.

†We used the linked PBS data (April-June 2009), MBS data (April-June 2009) and APDC data (April-June 2009) to identify recent medication use, number of different doctors visited and recent hospitalisation during the 3 months prior to 1 July 2009, respectively.

APDC, admitted patient data collection; BMI, body mass index; HMR, home medicines review; LOTE, Language Other Than English; MBS,

Medicare Benefits Schedule; PBS, Pharmaceutical Benefits Scheme.

or among persons with different language backgrounds (table 2).

Further adjustment for number of medications substantially attenuated the observed age-sex adjusted association between HMR receipt and sociodemographic, behavioural and health-need factors (table 2). Having an HMR during 12 months prior to cohort baseline remained strongly associated with the HMR occurrence during the study period (table 2 ).

\section{Time-varying factors}

Considering time-varying factors specifically, HMR was more likely to occur in the study participants: dispensed greater numbers of medications; and dispensed medicines with NTI, in the Beers Criteria List or DBI; visiting greater number of different doctors; or being recently discharged from hospital, over time (table 3 ). Sensitivity analysis using backdated HMR receipt as the outcome variable demonstrated similar findings, except that recent hospitalisation was not significantly associated with subsequent HMR receipt (table 3). Further sensitivity analysis did not materially alter the main results (online supplementary table 1).

\section{DISCUSSION}

In this population-based prospective study, HMR receipt in older adults was higher in those who had characteristics consistent with high-risk medication use, particularly greater numbers of medications. Classes of medicines that are implicated in medication-related problems, including medicines with a NTI-(which are an indication for HMR) and medicines in the Beers Criteria or included in the DBI-(which are not formal indications for HMR) indicated an approximate twofold increase in HMR receipt, which were not strongly independently associated with HMR receipt, after adjustment for number of medications. Despite higher HMR use in those with polypharmacy and other markers of high-risk prescribing, over $90 \%$ of older adults with these markers did not receive an HMR over a 5-year period; an HMR was received by $8.3 \%$ of participants dispensed $\geq 5$ medications, $6.8 \%$ using Beers drugs, $8.8 \%$ using NTI drugs and $7.4 \%$ using DBI drugs.

The finding of a sevenfold higher HMR receipt in those with polypharmacy versus without polypharmacy provides novel population-based evidence that the HMR is, to some extent, being targeted. It is compatible with the finding of $7 \%$ increase (relative risk: $1.07,95 \%$ CI: 1.06 to 1.07 ) with the number of unique medications based on a veteran cohort in Australia which used a static approach adjusting for number of medications used in the year prior to the index date in a continuous scale. ${ }^{17}$ Differences in the definition and adjustment for number of medications may partly explain the larger relative effect estimates in the present analysis.

We also found a range of comorbid conditions were associated with increased HMR receipt, consistent with previous findings that HMR receipt increased among Australian veterans with dementia, heart failure and diabetes; and those with lower socioeconomic status. ${ }^{17}$ Factors widely reported to be associated with increased healthcare utilisation, such as rural/remote residence, 
Open access

Table 3 Time-varying exposures for HMR HR and its $95 \% \mathrm{Cl}$

\begin{tabular}{|c|c|c|c|}
\hline Time-varying drug exposure & HR $(95 \% \mathrm{Cl})^{*}$ & & \\
\hline Number of medications & All & Male & Female \\
\hline $0-4$ & 1.00 & 1.00 & 1.00 \\
\hline $5-9$ & 6.07 (5.58 to 6.59$)$ & 5.49 (4.87 to 6.18$)$ & 6.66 (5.92 to 7.48$)$ \\
\hline$\geq 10$ & $12.46(11.42$ to 13.59$)$ & 11.18 (9.88 to 12.66$)$ & $13.75(12.17$ to 15.54$)$ \\
\hline \multicolumn{4}{|l|}{ Polypharmacy } \\
\hline None (<5 drugs) & 1.00 & 1.00 & 1.00 \\
\hline Yes ( $\geq 5$ drugs) & 7.76 (7.16 to 8.41$)$ & 6.99 (6.24 to 7.83$)$ & 8.54 (7.62 to 9.57$)$ \\
\hline \multicolumn{4}{|l|}{ Beers drugs } \\
\hline No & 1.00 & 1.00 & 1.00 \\
\hline Yes & 2.91 (2.74 to 3.09 ) & 2.66 (2.44 to 2.89$)$ & 3.18 (2.92 to 3.47$)$ \\
\hline \multicolumn{4}{|l|}{ NTI drugs } \\
\hline No & 1.00 & 1.00 & 1.00 \\
\hline Yes & 2.32 (2.20 to 2.45$)$ & 2.55 (2.35 to 2.76$)$ & $2.16(2.00$ to 2.31$)$ \\
\hline \multicolumn{4}{|l|}{ DBI drugs } \\
\hline No & 1.00 & 1.00 & 1.00 \\
\hline Yes & 2.67 (2.53 to 2.81$)$ & 2.45 (2.27 to 2.64$)$ & 2.88 (2.68 to 3.10$)$ \\
\hline \multicolumn{4}{|l|}{ Hospitalisations } \\
\hline No & 1.00 & 1.00 & 1.00 \\
\hline Yes & 1.34 (1.11 to 1.61$)$ & 1.52 (1.19 to 1.94$)$ & 1.15 (0.87 to 1.52$)$ \\
\hline \multicolumn{4}{|l|}{ Number of different doctors } \\
\hline$\leq 2$ & 1.00 & 1.00 & 1.00 \\
\hline 3 or 4 & 3.04 (2.82 to 3.28$)$ & 2.91 (2.60 to 3.26 ) & 3.15 (2.85 to 3.48$)$ \\
\hline$\geq 5$ & 5.41 (5.04 to 5.82) & 5.37 (4.83 to 5.98$)$ & 5.44 (4.94 to 5.99$)$ \\
\hline
\end{tabular}

Sensitivity analysis for HMR dated back 90 days based on date of service

\begin{tabular}{|c|c|c|c|}
\hline Number of medications & All & Male & Female \\
\hline $0-4$ & 1.00 & 1.00 & 1.00 \\
\hline $5-9$ & 3.18 (2.97 to 3.40 ) & 3.10 (2.81 to 3.42 ) & 3.25 (2.96 to 3.57 ) \\
\hline$\geq 10$ & 5.80 (5.39 to 6.24$)$ & 5.83 (5.24 to 6.48$)$ & 5.78 (5.23 to 6.40$)$ \\
\hline \multicolumn{4}{|l|}{ Polypharmacy } \\
\hline None (<5 drugs) & 1.00 & 1.00 & 1.00 \\
\hline Yes ( $\geq 5$ drugs) & 3.88 (3.64 to 4.14 ) & 3.82 (3.49 to 4.19$)$ & 3.93 (3.60 to 4.29 ) \\
\hline \multicolumn{4}{|c|}{ Beers Criteria list medicines } \\
\hline No & 1.00 & 1.00 & 1.00 \\
\hline Yes & 1.97 (1.87 to 2.08 ) & 1.89 (1.75 to 2.04$)$ & 2.05 (1.90 to 2.21$)$ \\
\hline \multicolumn{4}{|l|}{ NTI medicines } \\
\hline No & 1.00 & 1.00 & 1.00 \\
\hline Yes & 1.87 (1.77 to 1.97$)$ & 2.06 (1.91 to 2.23 ) & 1.72 (1.60 to 1.85$)$ \\
\hline \multicolumn{4}{|l|}{ DBI medicines } \\
\hline No & 1.00 & 1.00 & 1.00 \\
\hline Yes & 1.99 (1.90 to 2.09$)$ & 1.90 (1.77 to 2.05$)$ & 2.08 (1.94 to 2.22 ) \\
\hline \multicolumn{4}{|l|}{ Hospitalisations } \\
\hline No & 1.00 & 1.00 & 1.00 \\
\hline Yes & 0.98 (0.80 to 1.20$)$ & 0.83 (0.61 to 1.13$)$ & 1.13 (0.87 to 1.48$)$ \\
\hline \multicolumn{4}{|l|}{ Number of different doctors } \\
\hline$\leq 2$ & 1.00 & 1.00 & 1.00 \\
\hline
\end{tabular}


Table 3 Continued

Time-varying drug exposure $\mathrm{HR}(95 \% \mathrm{Cl})^{*}$

\begin{tabular}{llllr}
\hline Number of medications & All & Male & Female \\
\cline { 4 - 5 } 3 or 4 & $2.54(2.37$ to 2.72$)$ & 2.40 (2.16 to 2.66) & 2.66 (2.42 to 2.92) \\
$\geq 5$ & 4.36 (4.09 to 4.66) & 4.36 (3.96 to 4.81) & 4.36 (3.99 to 4.77) \\
\hline
\end{tabular}

*HR was estimated for the entire study population $(n=131483)$ and stratified by age and/or sex controlling for listed time-varying medication and hospital care exposures only.

DBI, Drug Burden Index; HMR, home medicines review; NTI, Narrow Therapeutic Index.

lower educational attainment and lower household income were also associated with increased HMR receipt. Since these groups are also at increased risk of certain relevant health problems, this potentially reflects appropriate prioritisation by GPs assessing the need for HMR services. ${ }^{5}$ Although poorer health functioning and/ or reduced access to healthcare would be expected to have considerable independent relevance to medication safety, their relationship to HMR receipt in the current cohort was largely explained by the number of medications; however, these factors are difficult to quantify separately. Population subgroups at risk of adverse medication events could be considered to be at greater need than others for an HMR, including older males and individuals from culturally and linguistically diverse backgrounds. ${ }^{4}$ There was no difference in HMR receipt among males and participants with a LOTE background compared with other cohort members. These findings appear to differ from some previous findings. ${ }^{417}$ Nevertheless, the findings emphasise the need to continue efforts to reach targeted population subgroups, including those experiencing high-risk prescribing.

Although the optimal use of the HMR is unknown, the overall HMR coverage of $4.7 \%$ in the study population of concession-card holders and particularly the $8.3 \%$ in those taking five and more medications appears low, especially as it is recommended in the latter group. Through almost a decade since the landmark qualitative review of HMR conducted in $2008,{ }^{4}$ much attention has been given to increasing HMR use. Previous studies reported HMR constraints from GPs', pharmacists' and patients' perspectives, including limited resources, limited time, low health literacy and low awareness. ${ }^{4} 1516$ Several changes have been made to facilitate HMR services such as allowing GPs to refer HMR services directly to an accredited pharmacist to enhance GP-pharmacist communication. ${ }^{37}$ However, few patient-centred strategies have been attempted. Sustained commitment and initiatives to empower GPs, pharmacists and patients in particular, may have the potential to increase HMR receipt and maximise its benefits.

Current recommendations also encourage HMR for patients recently discharged from hospital. ${ }^{12}{ }^{13}$ We found a significant 34\% higher HMR receipt (HR: 1.34; 95\% CI: 1.11 to 1.61 ) in association with recent hospital care in older Australians, which is not inconsistent with the previous finding of $9 \%$ increase (relative risk: 1.09; 95\% CI: 1.04 to 1.16 ) among veterans having an annual 1-2 hospitalisations compared with those having no hospitalisation. ${ }^{17}$ In the sensitivity analysis using backdated HMR receipt to account for the possible different medication exposure scenario between requesting and undertaking HMR, we did not find a statistically significant association between recent hospital care and increased HMR receipt.

This study had a large sample size and was able to investigate prospectively a large number of factors using validated measures. Findings include the relation of HMR to a range of previously uninvestigated factors and provide more robust evidence on results which were largely consistent with previous studies. We were also able to account for a range of different health-need factors and to consider to what extent observed relationships were explained by the strong relation of HMR to polypharmacy. For missing values of some confounding factors, we neither attempted to conduct complete analysis nor multiple imputations without knowledge of the missingness mechanisms. A separate missing category was modelled in the RR estimation without reduction in sample size and statistical efficiency, and these variables with missing values were not considered in the Cox regression models. Although bias due to measurement errors was deemed minimal, appropriate care should be given to interpreting results. The observed associations with different medication factors were robust and did not change materially after a series of sensitivity analyses, in particular when updating medication exposure during the study period. A limitation of this study is that we lack complete information which GPs used to assess the HMR needs of their patients, for example, precise daily dose information, adherence to medications and adverse symptoms and signs in relation to medicines. The consistency of findings across different medication-related factors and following sensitivity analyses indicate that these unmeasured factors are unlikely to overly influence the observed results, although this possibility cannot be excluded completely. Absolute proportions of individuals receiving HMR should be interpreted with caution because our study population of concession card holders is not directly representative of the general population; given the relative disadvantage and increased morbidity in this group, the observed proportions receiving an HMR may, if anything, be higher than in the general population. Moreover, observed relative risks are likely to be reliable. ${ }^{38}$ 
The study findings provide new evidence on factors associated with HMR and are likely to inform approaches to improve HMR service to reach patients of greater need. Although it is evident that increased HMR receipt among older adults has largely occurred among those with polypharmacy, the majority of older adults with polypharmacy and prescribed high-risk medicines have not had an HMR. Continuing efforts are warranted to extend its delivery to patients of greater need. Given the important role of HMR in Australian healthcare services, future research should also target its effectiveness in reducing high-risk prescribing and relevant health outcomes.

\section{Author affiliations}

${ }^{1}$ Research School of Population Health, Australian National University, Canberra, Sydney, Australia

${ }^{2}$ Sydney Pharmacy School and Centre for Education and Research on Ageing, University of Sydney and Concord Hospital, Sydney, New South Wales, Australia ${ }^{3}$ Charles Perkins Centre, University of Sydney, Sydney, New South Wales, Australia ${ }^{4}$ Centre for Big Data Research in Health, University of New South Wales, Sydney, New South Wales, Australia

${ }^{5}$ Kolling Institute of Medical Research, Sydney Medical School, Royal North Shore Hospital, University of Sydney, North Shore, Sydney, Australia

${ }^{6}$ Centre for Education and Research on Ageing, Sydney Medical School University of Sydney, Camperdown, Camperdown, Australia

${ }^{7}$ Centre for Health Economics Research Eval., University of Technology, Sydney, New South Wales, Australia

${ }^{8}$ The Sax Institute, Sydney, New South Wales, Australia

Acknowledgements This research was completed using data collected through the 45 and Up Study (www.saxinstitute.org.au). The 45 and Up Study is managed by the Sax Institute in collaboration with major partner Cancer Council NSW; and partners: the National Heart Foundation of Australia (NSW Division); NSW Ministry of Health; NSW Government Family and Community ServicesAgeing, Carers and the Disability Council NSW; and the Australian Red Cross Blood Service. We thank the many thousands of people participating in the 45 and Up Study.

Contributors EB made substantial contributions to study conception, design, and data acquisition. WD was a major contributor in the study design, data analysis, result interpretation and the first draft. DG, S-AP, SNH, AJM, FB, RV, GJ and $C D$ contributed to design, analysis and interpretation of data and revising the manuscript critically for important intellectual content. All authors read and approved the final manuscript.

Funding This study is funded by the National Health and Medical Research Council of Australia (Project Grant 1024450 and the NHMRC Centre of Research Excellence in Medicines and Ageing (1060407). EB and DG are supported by the NHMRC.

Competing interests None declared.

Patient consent for publication Not required.

Ethics approval The conduct of the 45 and Up Study was approved by the University of New South Wales Human Research Ethics Committee. Data linkage through the CHeReL was approved by the NSW Population and Health Services Research Ethics Committee. The NSW Population and Health Services Human Research Ethics Committee and the Australian National University Human Research Ethics Committee approved the study (HREC/12/CIPHS/31).

Provenance and peer review Not commissioned; externally peer reviewed.

Data sharing statement Information about data access and governancepolicies is available at https://www.saxinstitute.org.au/for-researchers/.

Open access This is an open access article distributed in accordance with the Creative Commons Attribution Non Commercial (CC BY-NC 4.0) license, which permits others to distribute, remix, adapt, build upon this work non-commercially, and license their derivative works on different terms, provided the original work is properly cited, appropriate credit is given, any changes made indicated, and the use is non-commercial. See: http://creativecommons.org/licenses/by-nc/4.0/.

\section{REFERENCES}

1. Elliott RA, C. Booth J. Problems with medicine use in older Australians: a review of recent literature. Journal of Pharmacy Practice and Research 2014;44:258-71.

2. Roughead EE, Anderson B, Gilbert AL. Potentially inappropriate prescribing among Australian veterans and war widows/widowers. Intern Med J 2007;37:402-5.

3. Atkin PA, Veitch PC, Veitch EM, et al. The epidemiology of serious adverse drug reactions among the elderly. Drugs Aging 1999;14:141-52.

4. Department of Health and Ageing. Campbell research and consulting. home medicines review program qualitative research project: Medication Management and Research Section, 2008.

5. Pharmaceutical Society of Australia. Guidelines for pharmacists providing home medicines review (hmr) services final report as part of the fifth community pharmacy agreement. Australia: Pharmaceutical Society of Australia, 2011.

6. Beuscart JB, Pont LG, Thevelin S, et al. A systematic review of the outcomes reported in trials of medication review in older patients: the need for a core outcome set. Br J Clin Pharmacol 2017;83:942-52.

7. Renaudin P, Boyer L, Esteve MA, et al. Do pharmacist-led medication reviews in hospitals help reduce hospital readmissions? A systematic review and meta-analysis. Br J Clin Pharmacol 2016;82:1660-73.

8. Chen TF. Pharmacist-led home medicines review and residential medication management review: the australian model. Drugs Aging 2016;33:199-204.

9. Jokanovic N, Tan EC, van den Bosch D, et al. Clinical medication review in Australia: a systematic review. Res Social Adm Pharm 2016;12:384-418.

10. Roughead EE, Barratt JD, Ramsay E, et al. The effectiveness of collaborative medicine reviews in delaying time to next hospitalization for patients with heart failure in the practice setting: results of a cohort study. Circ Heart Fail 2009;2:424-8.

11. Roughead EE, Barratt JD, Ramsay E, et al. Collaborative home medicines review delays time to next hospitalization for warfarin associated bleeding in Australian war veterans. J Clin Pharm Ther 2011;36:27-32.

12. Australian Government Department of Health. Medicare benefit schedule book: operating from 2014. Canberra: Department of Health, 2014.

13. Department of Health and Pharmacy Guild Australia. Programme specific guidelines: home medicines review (HMR): Final report as part of the Fifth Community Pharmacy Agreement, 2014.

14. March G. Update on professional services: home medicines review. 16. Australia: Professional Pharmacists Australia, 2015.

15. Ponniah A, Shakib S, Doecke CJ, et al. Post-discharge medication reviews for patients with heart failure: a pilot study. Pharm World Sci 2008;30:810-5.

16. Lee CY, George J, Elliott RA, et al. Exploring stakeholder perspectives on medication review services for older residents in retirement villages. Int J Pharm Pract 2012;20:249-58.

17. Ellett LMK, Ramsay EN, Barratt JD, et al. Home medicines reviews: extent of uptake by high-risk veterans. Journal of Pharmacy Practice and Research 2013;43:182-6.

18. Lee CY, George J, Elliott RA, et al. A pharmacist-led intervention for increasing the uptake of home medicines review (hmr) among residents of retirement villages (PHARMER): protocol for a cluster randomised controlled trial. BMC Health Serv Res 2011;11:292.

19. Costa D, Van C, Abbott $P$, et al. Investigating general practitioner engagement with pharmacists in home medicines review. $J$ Interprof Care 2015;29:469-75.

20. Banks E, Redman S, Jorm L, et al. Cohort profile: the 45 and up study. Int J Epidemiol 2008;37:941-7.

21. NSW. NSW Centre for health record linkage. www.cherel.org.au (Accessed July 2017).

22. Gnjidic D, Le Couteur DG, Pearson SA, et al. High risk prescribing in older adults: prevalence, clinical and economic implications and potential for intervention at the population level. BMC Public Health 2013;13:115.

23. Australian Government Department of Health. The Safety net scheme. http://www.pbs.gov.au (Accessed 01 Feb 2017).

24. Andersen R, NEWMAN JF. Societal and individual determinants of medical care utilization in the United States. Milbank Q 2005;83.

25. Australian Government Department of Health and Aged Care. Measuring Remoteness: accessibility/Remoteness Index of Australia (ARIA). Canberra: Department of Health and Aged Care, 2001.

26. Haley SM, McHorney CA, Ware JE. Evaluation of the MOS SF-36 physical functioning scale (PF-10): I. Unidimensionality and reproducibility of the Rasch item scale. J Clin Epidemiol 1994;47:671-84. 
27. Kessler RC, Andrews G, Colpe LJ, et al. Short screening scales to monitor population prevalences and trends in non-specific psychological distress. Psychol Med 2002;32:959-76.

28. WHO Collaborating Centre for Drug Statistics Methodology. The Anatomical therapeutic chemical classification system. Oslo: WHO Collaborating Centre for Drug Statistics Methodology. Norwegian Institute of Public Health, 2015.

29. Gnjidic D, Du W, Pearson SA, et al. Ascertainment of self-reported prescription medication use compared with pharmaceutical claims data. Public Health Res Pract. In Press. 2017;27.

30. King MA, Purdie DM, Roberts MS. Matching prescription claims with medication data for nursing home residents: implications for prescriber feedback, drug utilisation studies and selection of prescription claims database. J Clin Epidemiol 2001;54:202-9.

31. Poudel A, Peel NM, Nissen LM, et al. Adverse outcomes in relation to polypharmacy in robust and frail older hospital patients. J Am Med Dir Assoc 2016;17:767.e9-13.
32. Birkett D. Therapeutic drug monitoring. Aust Prescr 1997;20:9-11.

33. Ministry of Health. NSW Ministry of Health. High-Risk Medicines Management Policy. Sydney: Ministry of Health, 2015.

34. Society AG, Society AG. American geriatrics society 2015 updated beers criteria for potentially inappropriate medication use in older adults. J Am Geriatr Soc 2015;63:2227-46.

35. Hilmer SN, Mager DE, Simonsick EM, et al. Drug burden index score and functional decline in older people. Am J Med 2009;122:1142-9.

36. Page E, Kemp-Casey A, Korda R, et al. Using Australian pharmaceutical benefits scheme data for pharmacoepidemiological research: challenges and approaches. Public Health Res Pract 2015;25:e2541546.

37. Bereznicki L. Changes to HMR business rules. . Australian: Australian Pharmacist, 2012:31. 186.

38. Mealing NM, Banks $E$, Jorm LR, et al. Investigation of relative risk estimates from studies of the same population with contrasting response rates and designs. BMC Med Res Methodol 2010;10:26. 